\title{
HSUMB Newsletter
}

\author{
Hellenic Society for Ultrasound in Medicine and Biology
}

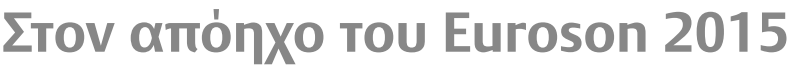

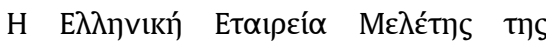

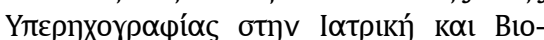

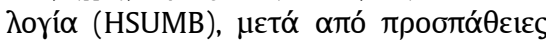

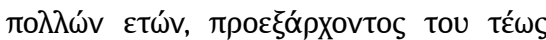

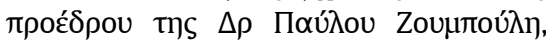

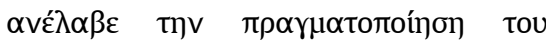

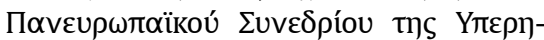

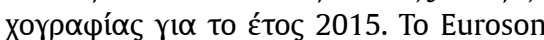

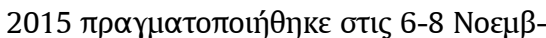

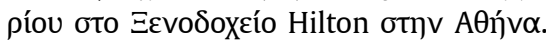

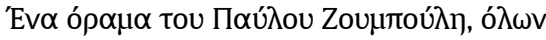

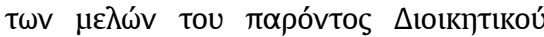

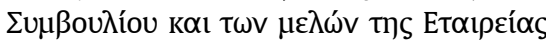

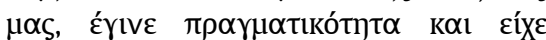

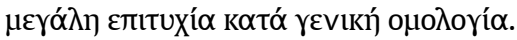

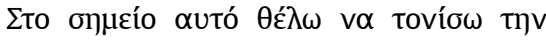

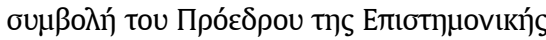

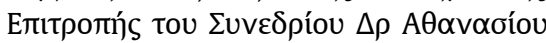

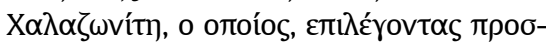

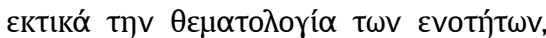

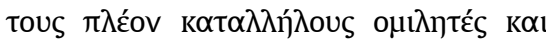

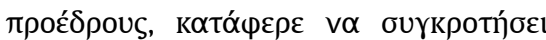

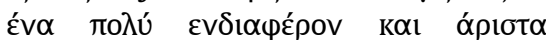

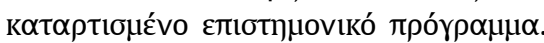

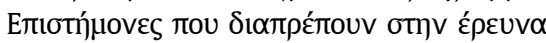

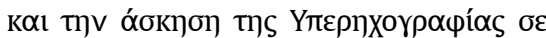

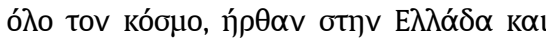

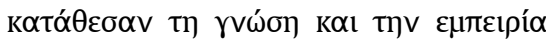
TOUৎ бTo EUROSON 2015.

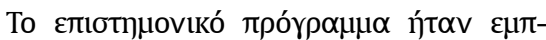

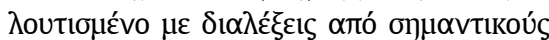

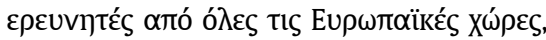

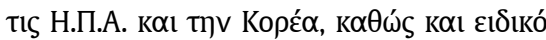

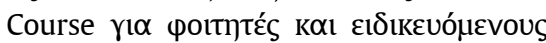

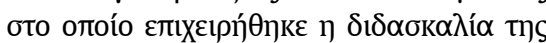

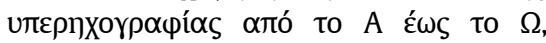

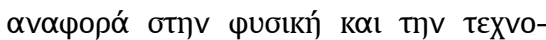

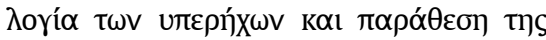

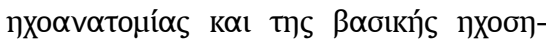

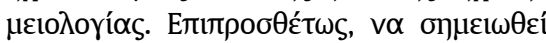

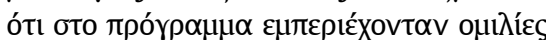

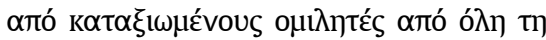

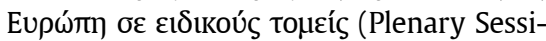

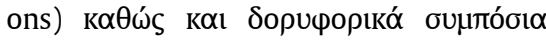

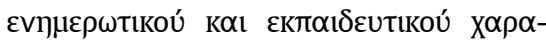

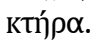

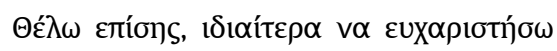

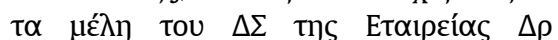

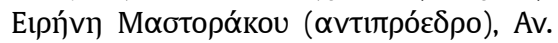

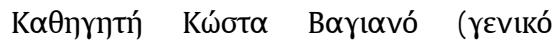

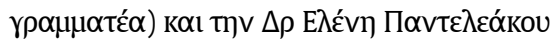

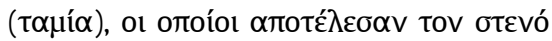

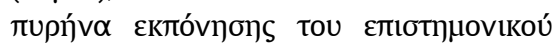

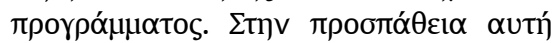

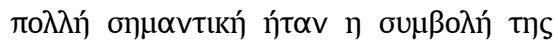

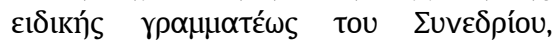

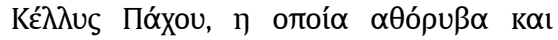

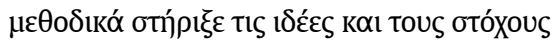

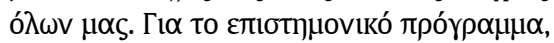

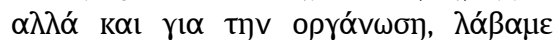

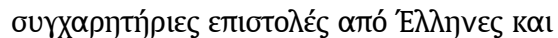

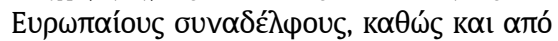

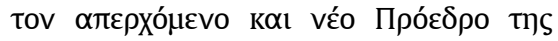

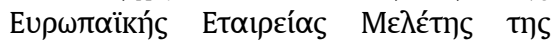

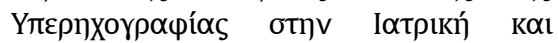

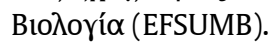

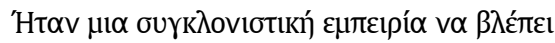

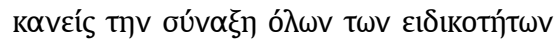

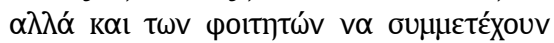

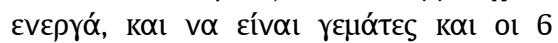

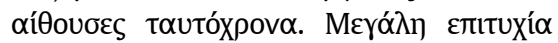

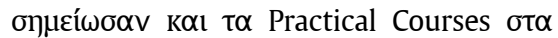

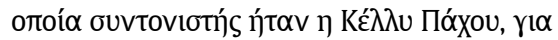

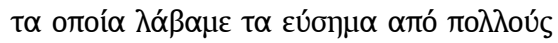

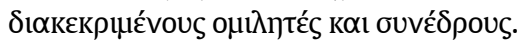

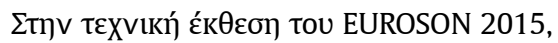

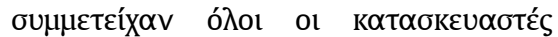

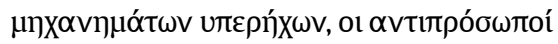

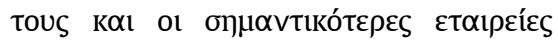

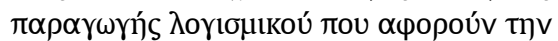

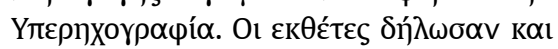

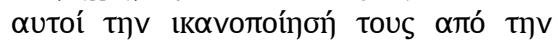

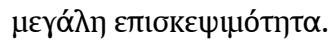

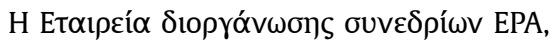

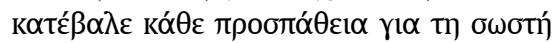

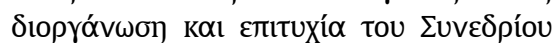

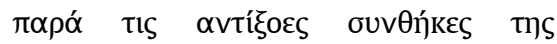

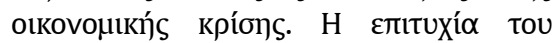

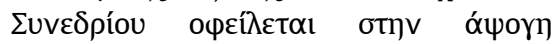

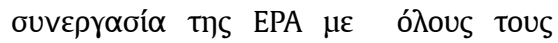

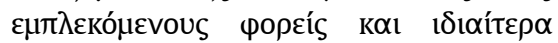

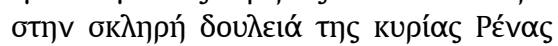

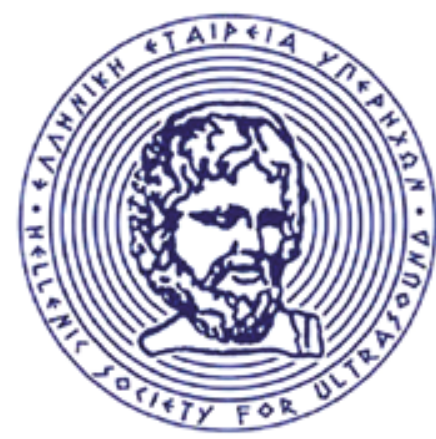

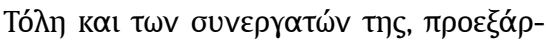

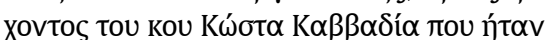

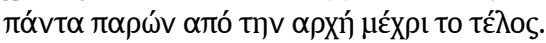

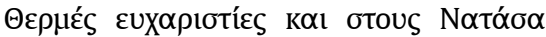

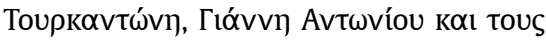

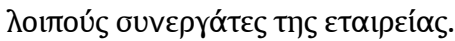

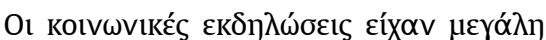

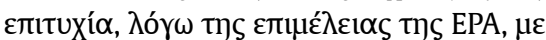

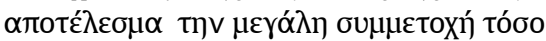

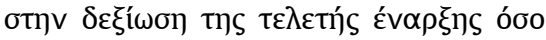

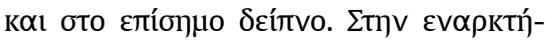

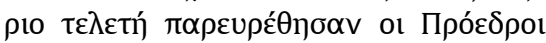

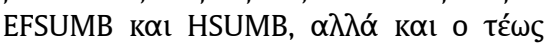

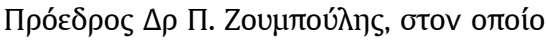

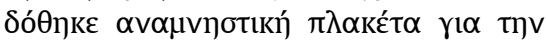

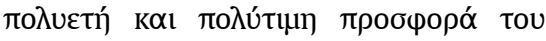

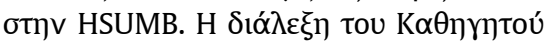

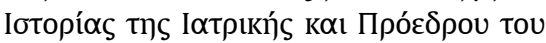

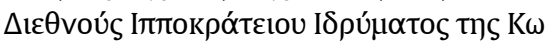

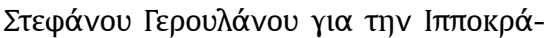

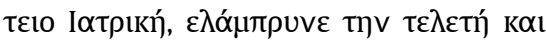

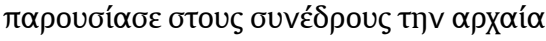

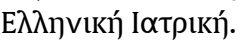

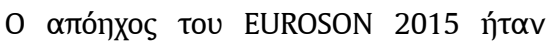

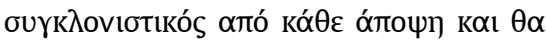

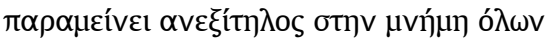

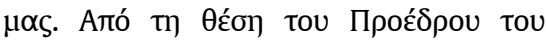

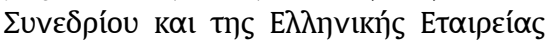

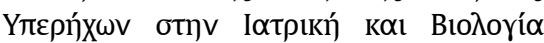

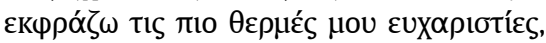

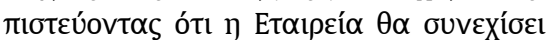

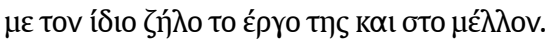

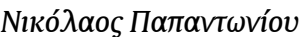

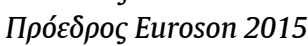

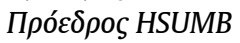

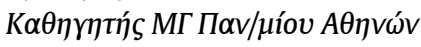

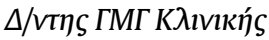

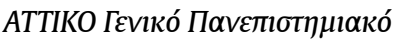

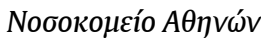

\section{Address}

Nikolaos Papantoniou MD PhD

Vas. Sofias 82

Athens, Greece

info@hsumb.gr 


\section{ศELROSON2015}

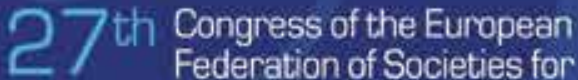

Ultrasound in Medicine and

Biology (EFSUMB)

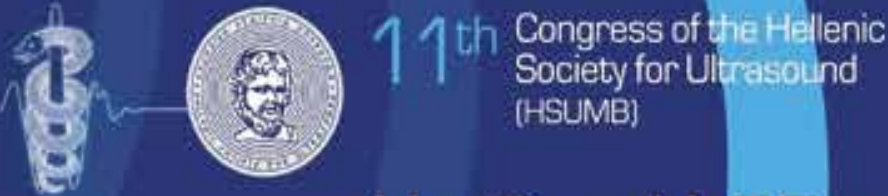

UitraSound $U_{p}$ GRades prevention/diagnosis/therapy

Athens Greece, November 6-8

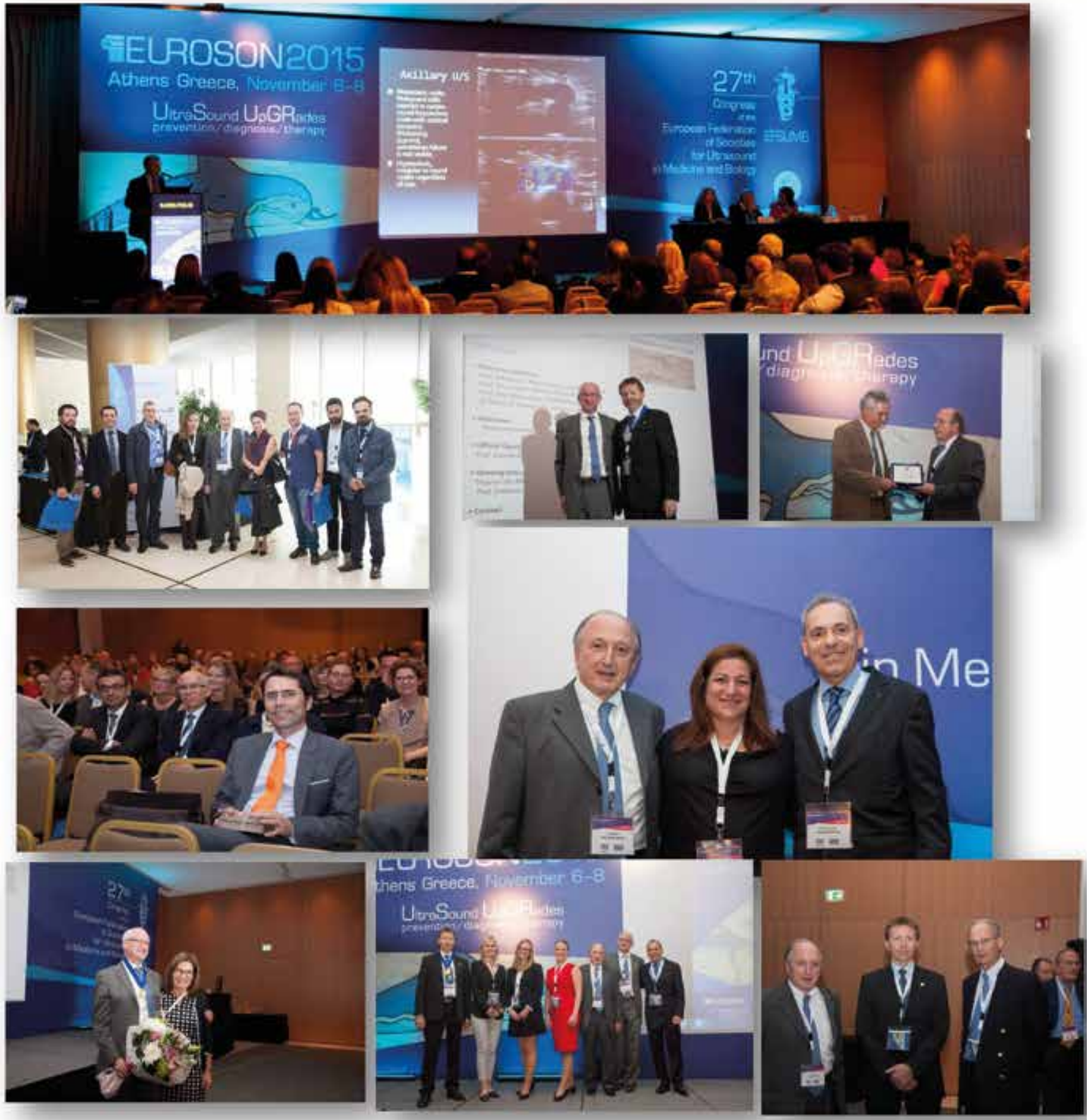

